STRUCTURAL BIOLOGY

ISSN 2059-7983

\title{
Introduction to Protein Science. Architecture, Function and Genomics. Third Edition. By Arthur M. Lesk. Oxford University Press, 2016. Pp. 466. Paperback. Price GBP 39.99. ISBN 9780198716846.
}

\author{
Claude Didierjean $^{\mathrm{a}, \mathrm{b} *}$ and Frédérique Tête-Favier ${ }^{\mathrm{a}, \mathrm{b}}$ \\ a Université de Lorraine, CRM2, UMR 7036, Vandoeuvre-les-Nancy, F-54506, France, and ${ }^{\mathbf{b}} \mathrm{CNRS}, \mathrm{CRM} 2, \mathrm{UMR} 7036$, \\ Vandoeuvre-les-Nancy, F-54506, France. *Correspondence e-mail: claude.didierjean@univ-lorraine.fr
}

Keywords: book reviews; protein science; protein architecture; protein function; genomics.

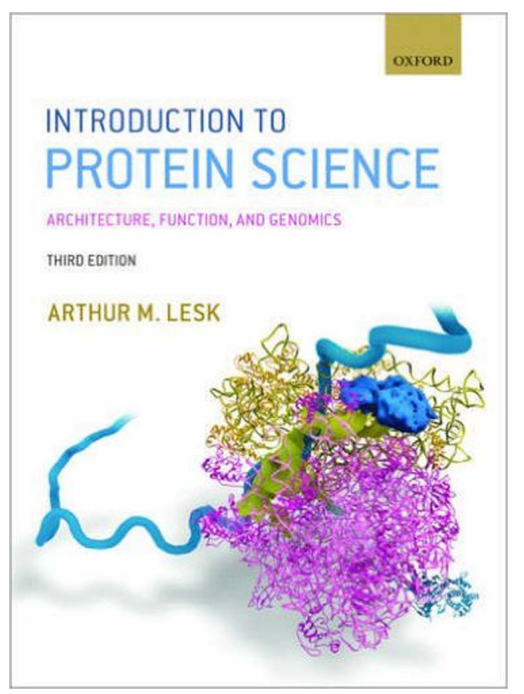

(C) 2016 International Union of Crystallography
The third edition of Introduction to Protein Science continues to be a brilliant superior textbook for undergraduate and new postgraduate students in biology and chemistry. It would be difficult to express the qualities of this book better than Doolittle (2005) in his review of the first edition: 'How can a book with only seven chapters cover so many topics so thoroughly and so well? For one thing, Lesk is a gifted writer with a knack for making complex material eminently understandable. For another, he has managed an adroit balancing of the carefully crafted main text with dozens of well-situated "boxes" and "case studies", each of which provides intriguing connections to the subject at hand'. This new edition is, above all, an excellent update of the previous one, and includes an enriched bibliography at the end of each chapter with recent reviews of many topics.

Like the previous editions, the third one is written as a series of lectures including fundamentals and detailed examples. Each chapter begins with clearly specified learning goals and finishes with exercises and problems. The 'weblems' (web-based problems) do not appear in the text as in the previous editions but only on the companion website. The plan of the book, separated into nine chapters, is similar to that of the second edition, as is the number of pages (466 versus 454 ), probably to maintain a readable balanced work.

Chapter 1 gives an overview of all the subjects that are discussed in detail later in the book. Notably, one section now emphasises the disorder in proteins as a very important point to consider in structure-function relationship studies. Chapter 2 Protein structure is a key chapter and most sections are important. The data banks of protein structure classifications have been updated and now include the new database SCOP2. Chapter 3 covers experimental and computational methods of protein structure determination (X-ray crystallography, NMR spectroscopy, cryo-electron microscopy and modelling methods). Most of the sections have been updated to emphasise promising methods such as serial femtosecond crystallography (which is used to follow the very early events of enzymatic reactions) or solid-state NMR spectroscopy (used today to determine membrane-protein structures). Although very recent results from cryo-EM are briefly presented, this widely practised method could have been described more in detail, as is done for XRD and NMR.

Chapter 4 focuses on how to retrieve information from databases and how to perform sequence alignments and structure superimpositions. The fifth chapter explores the basic concepts of enzymology and the sixth the principles of protein-biomacromolecule interactions, illustrated with a range of examples. These three important chapters have not been substantially modified with respect to the previous editions. After a repetition of the basic principles of the evolutionary relationships among proteins, the seventh chapter discusses the evolution aspects through case studies. In the case of evolution of the enolase superfamily, the relationships between sequences is now examined using a protein sequence similarity network, which is a powerful tool developed by the research group of P. Babbit (Brown \& Babbitt, 2012). The phage display technique also enriches the direct evolution section. Chapter 8 is a clear introduction to the concepts of protein folding and stability. The ninth and final chapter is probably the most contemporary part 
dealing with proteomics and systems biology. The RNAsequencing section constitutes a significant addition which includes a very interesting comparison between RNAseq and microarray techniques.

Martz (2005) and Doolittle (2005) in the reviews of the first edition, both considered the presence of figures as stereo-pairs to be a good thing. Martz regretted the lack of explanations of how to see the stereoviews and Doolittle reported the wrong format of about one fifth of the paired figures. The stereoviews have not been included in the third edition. This gap will probably be filled by the companion website which provides rotating structures from the book, and this point could have been discussed in the preface of this new edition.
In summary, this book provides a very good basic introduction to selected topics in protein science. Through this new edition, the author has successfully updated the previous one. It is recommended reading for a course in protein chemistry and enzymology, and could be read with interest by anyone with a chemistry background wishing to learn more details about protein function.

\section{References}

Brown, S. D. \& Babbitt, P. C. (2012). J. Biol. Chem. 287, 35-42. Doolittle, R. (2005). BioEssays, 27, 860-861.

Martz, E. (2005). Biochem. Mol. Biol. Edu. 33, 2, 144-146. 